ISSN 1981-416X

Licenciado sob uma Licença Creative Commons

\title{
Dispositivo de inovação: produção da/o estudante ativa/o no ensino superior ${ }^{1}$
}

\author{
Innovation device: production of the \\ active student in higher education
}

Dispositivo de innovación: producción de la/del estudiante activa/o en la enseñanza superior

\section{Rafaela Esteves Godinho Leal, Shirlei Rezende Sales*}

Universidade Federal de Minas Gerais (UFMG), Belo Horizonte, MG, Brasil

\section{Resumo}

As/os professoras/es do ensino superior são convocadas/os a inovar em suas práticas educacionais, utilizando metodologias que favoreçam a produção de estudantes ativas/ os. Estas/es são caracterizadas/os pela autonomia, protagonismo e participação nas atividades de aprendizagem. As/os discentes são incitadas/os, assim, a autogovernarem suas condutas no sentido de se corresponsabilizarem por suas aprendizagens. Nessa direção,

${ }^{1} \mathrm{O}$ presente artigo traz resultados da pesquisa registrada em: LEAL, R. E. G. Dispositivo de inovação no ensino superior: a produção do docentis innovatus e discipulus iacto. Dissertação (Mestrado) Faculdade de Educação, Universidade Federal de Minas Gerais, Belo Horizonte, 2017.

*SRS: Doutora em Educação, e-mail: shirlei.sales@hotmail.com REGL: Mestre em Educação, e-mail: rafaelegodinho@yahoo.com.br 
este artigo tem como objetivo analisar as técnicas discursivas acionadas na produção dessa/e estudante autônoma/o e protagonista da sua formação. O corpus da investigação é constituído pelos ditos em circulação nos Projetos Pedagógicos de Cursos de Graduação (PPC), em um curso na modalidade a distância de formação de professoras/es universitárias/os, bem como entrevistas realizadas com participantes dessa formação. Utilizaram-se como referencial as ferramentas teóricas e analíticas do filósofo Michel Foucault, a saber: dispositivo, discurso, poder, técnica e autogoverno. Por meio da rede metodológica que articulou elementos da netnografia educacional, de entrevistas narrativas e da análise do discurso de inspiração foucaultiana desenvolveu-se o argumento de que a autonomia, a participação e o protagonismo são acionados como técnicas de governo que incidem sobre a conduta das/os estudantes e se integram ao dispositivo de inovação. Conclui-se que a produção dessa/e discente ativa/o atende ao funcionamento da "sociedade da inovação".

Palavras-chave: Inovação. Dispositivo. Protagonismo. Autonomia. Autogoverno.

\begin{abstract}
Higher education teachers are invited to innovate in their educational practices, using methodologies that favor the production of active students. These are characterized by autonomy, protagonism and participation in learning activities. The students are therefore encouraged to self-govern their behaviors in order to be jointly responsible for their learning. In this direction, this article aims to analyze the discursive techniques triggered in the production of this autonomous student who is the protagonist of their formation. The corpus of the research is constituted by the circulating sayings in the Pedagogical Projects of Undergraduate Courses (PPC), in a course in the modality distance of training of university teachers, as well as interviews with participants of this training. The theoretical and analytical tools of the philosopher Michel Foucault were used as reference, namely: device, discourse, power, technique and self-government. Through the methodological network that articulated elements of educational netnography, narrative interviews and the analysis of Foucauldian-inspired discourse, the argument arose that autonomy, participation and protagonism are triggered as techniques of government that affect the conduct of students
\end{abstract}


and integrate themselves into the device of innovation. We conclude that the production of this active student serves the functioning of the "innovation society".

Keywords: Innovation. Device. Protagonism. Autonomy. Self-government.

\section{Resumen}

Las / los profesoras / es de la enseñanza superior son convocadas / os a innovar en sus prácticas educativas, utilizando metodologías que favorezcan la producción de estudiantes activos / as. Estas son caracterizadas por la autonomía, el protagonismo y la participación en las actividades de aprendizaje. Se les incita a los/las discentes a que se autogobiernen sus conductas en el sentido de corresponsabilizarse por sus aprendizajes. En esta dirección, este artículo tiene como objetivo analizar las técnicas discursivas accionadas en la producción de esa / y estudiante autónoma / o y protagonista de su formación. El corpus de la investigación está constituido por los dichos en circulación en los Proyectos Pedagógicos de Cursos de Graduación (PPC), en un curso en la modalidad a distancia de formación de profesoras / es universitarias / as, así como entrevistas realizadas con participantes de esa formación. Se utilizó como referencial las herramientas teóricas y analíticas del filósofo Michel Foucault, a saber: dispositivo, discurso, poder, técnica y autogobierno. Por medio de la red metodológica que articuló elementos de la red neuronal educativa, de entrevistas narrativas y del análisis del discurso de inspiración foucaultiana se desarrolló el argumento de que la autonomía, la participación y el protagonismo son accionados como técnicas de gobierno que inciden sobre la conducta de las conductas / los estudiantes y se integran al dispositivo de innovación. Se concluye que la producción de esa / y discente activa / o atiende al funcionamiento de la "sociedad de la innovación".

Palabras clave: Innovación. Dispositivo. Papel. Autonomía. Autogobierno. 


\section{Introdução}

Parece que a inovação se tornou um imperativo nos tempos atuais, sendo possível pensar em uma "sociedade da inovação" (LEAL, 2017). Nela, professoras/es e estudantes são convocadas/os a se tornarem inovadoras/es de um determinado modo. No caso das/os professoras/es, ainda de acordo com Leal (2017), elas/es são demandadas/os a atuarem como mediadoras/es e facilitadoras/es no ensino. Nessa condução da ação educativa, demanda-se que as/os professoras/es sejam inovadoras/es e para isso, nas aulas, utilizem metodologias ativas. Elas estão na ordem do discurso de inovação no ensino universitário e têm como alvo fabricar estudantes ativas/os. Assim, as/os professoras/es, para serem consideradas/os inovadoras/es no ensino, são incitadas/os a se preocuparem com a aprendizagem da/o estudante, mas no sentido de essa/e estudante se "autogovernar" (FOUCAULT, 1993), isto é, estabelecer uma relação com ela/e mesma/o para aprender. Em outras palavras, aprender a conduzir e controlar sua própria conduta para desenvolver a aprendizagem. É divulgado que, para isso, as/os discentes precisam "ser autônomas/os", "protagonistas do seu aprendizado" e "corresponsabilizar-se por sua formação". Neste artigo, analisamos como essas demandas discursivas podem se constituir em técnicas de governo, ou melhor, técnicas que incidem sobre as condutas ou ações das/os discentes, produzindo a/o estudante ativa/o que nomeamos como discipulus iacto. Investigamos essa produção na pesquisa de mestrado "Dispositivo de inovação no ensino superior: a produção do docentis innovatus e discipulus iacto".

Como resultado de tal investigação, este artigo tem como objetivo analisar as técnicas discursivas acionadas na produção dessa/e estudante autônoma/o e protagonista da sua formação. O corpus da investigação é constituído pelos ditos em circulação nos Projetos Pedagógicos de Cursos de Graduação (PPC) e no curso a distância de formação continuada de professoras/es universitárias/os, bem como entrevistas realizadas com participantes dessa formação. 
Utilizaram-se como referencial as ferramentas teóricas e analíticas do filósofo Michel Foucault, a saber: dispositivo, discurso, poder, técnica e autogoverno. Por meio da rede metodológica que articulou elementos da netnografia educacional, de entrevistas narrativas e da análise do discurso de inspiração foucaultiana desenvolveu-se o argumento de que a autonomia, a participação e o protagonismo são acionados como técnicas de governo que incidem sobre a conduta das/os estudantes e se integram ao dispositivo de inovação. Apresentamos, a seguir, a rede metodológica e a elaboração conceitual que serviu de referencial para a investigação e, logo após, analisamos as técnicas acionadas na fabricação da/o estudante ativa/o.

\section{Rede metodológica}

Escolhemos a netnografia educacional como um dos caminhos metodológicos, visto que realizamos a pesquisa em um curso de formação continuada de professoras/es, os "Percursos Formativos em docência do ensino superior", ofertado na Universidade Federal de Minas Gerais (UFMG). As atividades dessa formação são ofertadas na modalidade de Educação a Distância (EAD), no Ambiente Virtual de Aprendizagem (AVA). A formação em EAD proporciona aos docentes participantes do Percurso flexibilidade de tempo e espaço na realização das atividades propostas, sejam on-line ou off-line. Nessa formação a distância, as/os professoras/es dialogam sobre suas práticas de ensino, trocam experiências sobre a docência e elaboram planos de ação, os quais visam inovar no ensino de graduação. Os ditos que circularam nesse ambiente proporcionaram o mapeamento das estratégias, técnicas e tecnologias colocadas em funcionamento, discursivamente, na produção da/o estudante ativa/o. Aliamos a netnografia educacional à entrevista narrativa e à análise do discurso de inspiração foucaultiana nessa rede metodológica.

Para Amaral, Natal e Viana (2008), a netnografia consiste na transposição da etnografia para o estudo de práticas comunicacionais mediadas por computador. Para Kozinets (2014, p. 62) a netnografia "é pesquisa observacional participante baseada em trabalho de campo 
online". Kozinets (2014, p. 62) argumenta que a netnografia "usa comunicações mediadas por computador como fonte de dados para chegar à compreensão etnográfica de um fenômeno cultural ou comunal”. Assim, a netnografia "amplia o leque epistemológico dos estudos em comunicação e cibercultura" (AMARAL; NATAL; VIANA, 2008, p. 35). Utilizamos a netnografia nesta pesquisa por meio da observação e participação nas atividades on-line do Percurso Formativo. A carga horária dessa formação é de sessenta horas, sendo dez horas presenciais e cinquenta horas a distância. Um tempo significativo da pesquisa de campo foi gasto no ambiente on-line do Percurso. Esse fato tornou necessária, portanto, a abordagem netnográfica.

Já a entrevista narrativa "permite ao/à narrador/a a elaboração de imagens de si, da/o outra/o e do mundo e a atribuição de significados às suas experiências, constituindo-se como forma discursiva privilegiada para a compreensão das interpretações dos sujeitos sobre si mesmos, numa possível invenção de si” (TEIXEIRA; PADUA, 2006, não p.). Ao realizar e analisar as entrevistas não buscamos "verdades" a serem reveladas, mas procuramos entendê-las como "embebidas nos discursos de seu tempo, da situação vivida, das verdades instituídas para os grupos sociais" (SILVEIRA, 2007, p. 129). Para isso, tornou-se importante analisá-las buscando por regularidades e irregularidades discursivas, compondo, assim, a rede metodológica que articulou também a análise do discurso de inspiração foucaultiana.

Essa perspectiva tem como pressuposto o entendimento de que o discurso consiste em uma prática produtiva que fabrica saberes, verdades e subjetividades (FOUCAULT, 2015). Para Foucault (2015), o discurso veicula e produz poder. Sendo assim, os ditos sobre inovação mapeados nas entrevistas e no ambiente on-line do Percurso Formativo foram analisados buscando-se entender a produção da/o estudante ativa/o. Por isso, analisamos o discurso "tal qual ele é" (FOUCAULT, 2010, p. 253). Nessa perspectiva, não se procura encontrar, "por trás do discurso, alguma coisa que seria o poder e sua fonte" (FOUCAULT, 2010, p. 253). Mas examinamos "as diferentes maneiras pelas quais o discurso desempenha um papel 
no interior de um sistema estratégico em que o poder está implicado, e para o qual o poder funciona" (FOUCAULT, 2010, p. 253).

\section{Procedimentos utilizados para compor a rede metodológica}

Realizamos a investigação netnográfica com observação no ambiente on-line da sétima oferta do Percurso Formativo entre os meses de março a junho de 2016 com 140 inscritas/os. O Percurso está organizado em dez unidades temáticas. Tem-se o eixo geral, que é comum a todos os inscritos, e os eixos específicos, nos quais os/as participantes escolhem os temas mediante seus interesses formativos. Assim, tal formação oferece vários percursos para a/o cursista em uma única oferta, buscando garantir diversidade e personalização na formação continuada das/os professoras/ es universitárias/os. É importante notar que a modalidade EAD favorece essa organização curricular. O período de observação proporcionou uma imersão local, em que se buscou produzir as informações por meio da participação nas atividades on-line e também off-line do Percurso.

Realizamos também entrevistas narrativas com cinco professoras/es que participaram do Percurso Formativo e avaliaram que o curso forneceu elementos para inovarem em suas práticas de ensino. Selecionamos as/os docentes por meio da análise da atividade final do Percurso, em que elas/es entregaram o registro e/ou plano de ação pedagógico inovador. Entrevistamos cinco professoras/es, tendo o plano de ação como critério da seleção para participarem da etapa das entrevistas narrativas. Além disso, analisamos os Projetos Pedagógicos dos Cursos de Medicina, Enfermagem, Engenharia Ambiental e Física da UFMG. A escolha dos projetos desses cursos se justifica pelo nível de procura de docentes dessas áreas de conhecimento nas ofertas dos Percursos. De acordo com o Relatório 2010-2013 da UFMG (UFMG, 2014), as/os professoras/es da área de saúde são as/os que mais procuram pelo Percurso, enquanto docentes da área de exatas constituem um grupo com menor procura. Após a produção dessas informações, organizamo-las por suas 
regularidades e irregularidades discursivas para iniciar o procedimento de análise de discurso de inspiração foucaultiana (LEAL, 2017).

A pesquisa que subsidia o presente artigo (LEAL, 2017) se sustentou em princípios éticos, foi submetida e autorizada pelo Comitê de Ética em Pesquisa e apresentou o mínimo de riscos aos indivíduos em suas participações, seja por meio das entrevistas seja por meio da observação do ambiente virtual de aprendizagem. Para os registros, utilizamos nomes fictícios a fim de preservar o anonimato das/os participantes. A escolha por nomes de estrelas é uma homenagem aos docentes universitários. Todas/os as/os entrevistadas/os são doutoras/es e têm entre um e cinco anos de experiência docente na UFMG. A seguir, apresentamos as elaborações conceituais que servem de referencial teórico para este artigo.

\section{Dispositivo de inovação: urgência na produção do discipulus iacto}

Para o filósofo Michel Foucault, a produção de sujeitos está inscrita nos discursos. Isso porque os sujeitos nascem "num mundo que já é de linguagem, num mundo em que os discursos já estão há muito tempo circulando, nós nos tornamos sujeitos derivados desses discursos" (VEIGA-NETO, 2011, p. 91). É nessa perspectiva que Foucault analisa a linguagem e sua relação com o mundo. Para o autor, ela deve ser "estudada como uma coisa da natureza. Seus elementos têm, como os animais, as plantas ou as estrelas, suas leis de afinidade e de conveniência, suas analogias obrigatórias" (FOUCAULT, 1999, p. 48). De acordo com Leal (2017), é possível notar uma primazia da linguagem e do discurso nos estudos do filósofo e, principalmente, na perspectiva pós-estruturalista.

Entendendo a centralidade da linguagem e do discurso na formação dos sujeitos, pode-se observar que os discursos que circulam sobre inovação na docência universitária demandam tipos específicos de docentes e estudantes. Elas/es são fabricadas/os por meio da racionalidade do poder no nível das estratégias, das técnicas, das tecnologias. Nessa produção a docência inovadora é convocada pelo dispositivo de inovação a produzir sujeitos ativos, autônomos, competentes, competitivos e 
protagonistas da própria formação, constituindo, assim, a posição de sujeito discente ativa/o ou, no modo como aqui nomeamos, discipulus iacto (LEAL, 2017).

Dispositivo, para Foucault (2014, p. 364), trata-se do "conjunto decididamente heterogêneo que engloba discursos, instituições, organizações arquitetônicas, decisões regulamentares, leis, medidas administrativas, enunciados científicos, proposições filosóficas, morais, filantrópicas". Nesse sentido, o dispositivo engloba o dito e o não dito. Ele é "a rede que se pode estabelecer entre esses elementos" (p. 364). Dessa maneira, na perspectiva do autor (2014, p. 365), dispositivo é entendido como "um tipo de formação que, em um determinado momento histórico, teve como função principal responder a uma urgência. $O$ dispositivo tem, portanto, uma função estratégica dominante". Esse é o caso do dispositivo de inovação, que tem de responder à urgência da produção de sujeitos ativos, competitivos, criativos e autônomos, características da posição de sujeito discipulus iacto (LEAL, 2017).

Para desenvolver essa noção de posições de sujeito é necessário compreender o processo de subjetivação, o qual é acionado pelo dispositivo de inovação por meio da articulação de variados elementos. Esse processo se constrói a partir de articulações entre um conjunto de técnicas e tecnologias na formação de sujeitos de determinados tipos. Consideramos como tecnologia, na perspectiva foucaultiana, "a articulação de certas técnicas e de certos discursos acerca do sujeito" (FOUCAULT, 1993, p. 206). O processo de subjetivação se dá na interação entre as tecnologias de dominação dos indivíduos uns sobre os outros integrados a técnicas de si (FOUCAULT, 1993, p. 207). As "técnicas de dominação" estão relacionadas ao poder dos indivíduos uns sobre os outros, às técnicas de governo e às técnicas de coerção, ao passo que as "técnicas de si" se referem à relação consigo. Por meio das técnicas de si o sujeito é levado pelo discurso a fazer uma série de operações sobre si, exemplificadas por Foucault (1993) como o autoexame, o exame de consciência e a confissão. Nas técnicas de si os sujeitos efetuam "um certo número de operações sobre os seus corpos, 
sobre suas almas, sobre o seu próprio pensamento, sobre a sua própria conduta" (FOUCAULT, 1993, p. 207).

A integração entre as tecnologias de dominação e tecnologias de si é permeada por relações de poder. Na concepção foucaultiana, “o sujeito não constrói sentidos de maneira livre, mas sim por meio de diversos sistemas de restrições e incitações" (PARAÍSO, 2007, p. 54). De acordo com Machado (2014, p. 20), "o poder produz; ele produz o real; produz domínio de objetos e rituais de verdade. O poder possui uma eficácia produtiva, uma riqueza estratégica, uma positividade”. Ainda, segundo Machado (2014, p. 20), o objetivo do poder é gerir a vida dos homens, "controlá-los em suas ações para que seja possível e viável utilizá-los ao máximo, aproveitando suas potencialidades e utilizando um sistema de aperfeiçoamento gradual e contínuo de suas capacidades”. Desse modo, pode-se entender que o poder produz o sujeito. Neste artigo, entendemos o poder em sua positividade, queremos dizer, na sua vertente produtiva, e não como função exclusivamente repressiva. Pois, para Foucault (2014), o alvo do poder está em gerir os sujeitos, conduzindo suas condutas. Dito de outra maneira, o objetivo do poder é conduzir as ações dos sujeitos.

$\mathrm{Na}$ produção do discipulus iacto práticas reguladoras conduzem as condutas das/os estudantes, isto é, governam o modo de ser do/a estudante. Na acepção foucaultiana, de acordo com Leal (2017), a noção de governo é desenvolvida em três eixos. O primeiro está relacionado ao governo das/os outras/os - relação entre sujeitos - como "conjunto de ações sobre ações” (FOUCAULT, 2006, p. 237). No segundo eixo, há o autogoverno, isto é, o governo de si mesma/o, do estabelecimento da relação consigo mesma/o no sentido de se autodominar. Já o terceiro eixo é o governo sobre todas/os as/os outras/os, melhor dizendo, a "governamentalidade", cujo objeto de estudo se constitui nas maneiras de se governar a população (FOUCAULT, 2008). É no entrecruzamento desses eixos que a posição de sujeito discipulus iacto é produzida (LEAL, 2017). Em outras palavras, há um conjunto de ações que atuam sobre as condutas das/os estudantes; estes, por sua vez, operam sobre si as técnicas de autorregulação da aprendizagem e a autoavaliação. Essas formas de governo estão no 
registro da racionalidade neoliberal inscrita na "sociedade da inovação" (LEAL, 2017). Analisamos essas técnicas acionadas na fabricação da/o estudante ativa/o no próximo tópico.

\section{Protagonismo, participação e autonomia: técnicas na produção de estudantes ativas/os}

Assim, era visível o quanto era estimulado o protagonismo do estudante desde o início da disciplina, já que foi a turma que sugeriu os temas a serem tratados ao longo do semestre. (Trecho do Plano de ação - docente Rigel).

[...] no mundo moderno é imprescindível uma educação em que o estudante se transforme e seja protagonista de sua formação (UFMG, 2015, p. 45).

É possível observar um estímulo ao protagonismo estudantil no plano de ação de Rigel, uma vez que foram as/os discentes que sugeriram os temas trabalhados. Nesse sentido, elas/es participaram do processo de escolha do conteúdo. Para Leal (2017), há uma relação muito próxima entre "protagonismo" e "participação". Ferreti, Zibas e Tartuce (2004), em pesquisa realizada sobre esses termos, identificaram autoras/ es que fazem uso das expressões como sinônimos, chegando à conclusão de que não há uma clara distinção conceitual entre as expressões. Tendo em vista a etimologia do termo protagonismo, observa-se que protagnistés "significava o ator principal do teatro grego, ou aquele que ocupava o lugar principal em acontecimento" (FERRETI; ZIBAS; TARTUCE, 2004, p. 413). Tendo em vista essa origem, muitas/os autoras/es preferem utilizar a noção de "participação", a fim de garantir a ideia de participação democrática, evitando o destaque do protagonismo singular ou ator principal (FERRETI; ZIBAS; TARTUCE, 2004, p. 413). É possível pensar, portanto, haja vista a etimologia do termo protagonista, que a participação das/os discentes na disciplina pode ser caracterizada pelo processo 
democrático de escolha do conteúdo e/ou temas a serem desenvolvidos na disciplina, conforme trecho do plano de ação de Rigel.

No entanto, segundo Leal (2017), outros sentidos podem ser atribuídos ao protagonismo da/o estudante. Ferreti, Zibas e Tartuce (2004) discutem o protagonismo com vistas à formação cidadã das/os estudantes no sentido de atender às transformações sociais e culturais nos campos do trabalho, da ciência e da tecnologia, tendo efeitos sobre as práticas cotidianas, a vida social e a produção de subjetividades. As/os autoras/es salientam que as circunstâncias indicam "uma urgente necessidade social de promover, de maneira sistemática, a formação de valores e de atitudes cidadãs que permitam a esses sujeitos conviver de forma autônoma com o mundo contemporâneo" (p. 413). Em suas pesquisas, elas/ es identificaram discursos que circulam sobre protagonismo. De um lado as/os que advogam "a necessidade de desenvolvimento do ser humano completo, para além das necessidades de produção, aberto à diversidade cultural de seu tempo e às responsabilidades sociais" (p. 422). De outro lado, tem-se a face conservadora e economicista do discurso do protagonismo, orientando para adaptações à nova ordem mundial e à superação individual, ou seja, um ativismo social acrítico, segundo as/os autores.

Há incitações no sentido de a/o estudante se tornar protagonista da sua própria formação, como se pode observar no PPC do curso de Enfermagem, mencionado anteriormente, sendo "imprescindível", em outras palavras - imperioso, inevitável, urgente, essencial, uma educação em que a/o estudante "seja protagonista". Para Leal (2017), é possível notar que ação da/o estudante é conduzida para que ela/e se torne protagonista de sua aprendizagem. Ou seja, que ocupe o lugar principal e seja a/o primeira/o e, além disso, participe das decisões do seu processo de aprendizagem. Nesse sentido, o protagonismo é acionado como uma técnica de governo que incide sobre a conduta das/os estudantes, integrando-se ao dispositivo de inovação (LEAL, 2017).

A técnica de governo protagonismo presente no dispositivo de inovação pode acionar a competição entre os sujeitos. Souza (2011) destaca a origem grega do termo em que proto significa "o principal, o 
primeiro"; agon significa "luta" e agoniste significa "lutador" e "competidor". Assim, para ser a/o primeira/o é necessário competir com as/os outras/os, especialmente, consigo mesma/o e com suas condições de vida, a fim de protagonizar o seu processo de aprendizagem. Nesse sentido, ao operar como uma técnica de governo, o protagonismo pode produzir sujeitos ativos, autônomos e competitivos, atendendo às necessidades da "sociedade da inovação" (LEAL, 2017). Leite (2012, p. 34) entende o protagonismo como um indicador de inovação pedagógica em que há "participação consciente e autônoma de alunos e professores nos processos formativos". Corrobora essa ideia Cunha (2008), ao afirmar que o protagonismo constitui uma importante condição para a aprendizagem significativa e para a inovação, ao romper com a relação sujeito-objeto historicamente construída pela modernidade. A autora defende que o protagonismo reconhece as/os alunas/os e as/os professoras/es como sujeitos ativos das suas aprendizagens, compreendendo "a participação dos alunos nas decisões pedagógicas, a valorização da produção pessoal, original e criativa dos estudantes, estimulando processos intelectuais mais complexos e não repetitivos" (CUNHA, 2008, p. 27). Para Leal (2017),o protagonismo se faz presente nas ideias veiculadas pelas "escolas novas" difundidas no Brasil na década de 1930. Entretanto, elas são ressignificadas no ensino superior nos tempos atuais por meio do dispositivo de inovação. Nota-se, assim, uma continuidade discursiva entre protagonismo estudantil e docência universitária, entre docentis innovatus e discipulus iacto (LEAL, 2017).

É possível pensar, ainda, de acordo com Leal (2017, p. 137) "que se presencia uma responsabilização do sujeito sobre seu processo de aprendizagem como se houvesse uma homogeneidade no interior do grupo de estudantes". Para Ferreti, Zibas e Tartuce (2004), embora os/as estudantes possuam características comuns, há variações nas condições de vida deles, alertando-nos acerca de uma possível visão homogênea sobre os discentes.

Outra técnica de governo acionada nos discursos analisados, que integra o dispositivo de inovação, é a autonomia (LEAL, 2017). As 
inovações compõem um projeto para o desenvolvimento da aprendizagem pela autonomia, como é possível observar no plano de ação da docente Fomalhaut. Ela afirma que

A preocupação em construir conhecimentos com autonomia dos estudantes, em tempos e espaços diversos, de forma moderna e interativa, sinalizou a necessidade da aproximação de ferramentas didáticas, diferentes das tradicionais, capazes de contribuir para o compartilhamento e usufruto das potencialidades da sociedade moderna (Trecho do plano de ação - docente Fomalhaut).

Autonomia, segundo o dicionário Michaelis, é a "capacidade de autogovernar-se, de dirigir-se por suas próprias leis ou vontade própria; soberania"2. A autonomia, de acordo com Leal (2017), pode funcionar como uma técnica, quer dizer, aquilo que produz a conduta do sujeito autônomo. Ela é incitada no dispositivo de inovação para que as/os professoras/es a utilizem no sentido de estimular suas/seus estudantes a desenvolverem a autoaprendizagem (LEAL, 2017). Segundo Saraiva (2013), a autonomia, vista como controle de si, incumbe as/os discentes de mais responsabilidades e de serem gestoras/es de seus recursos, potencializando "a capacidade de cada sujeito realizar o governo de si" (SARAIVA, 2013, p. 21). Desse modo, cabe à/ao professora/or universitária/o delegar às/aos discentes a tarefa de aprender por meio de um trabalho que elas/es devem realizar sobre si mesmas/os.

Desse modo, as/os docentes do ensino superior são convocadas/ os a atuar como mediadoras/es nos processos de ensinar e aprender no intuito de fomentar o autogoverno discente para a atuação na "sociedade da inovação" (LEAL, 2017). Para Rué (2007), um/a estudante possui mais autonomia quando tem autocontrole sobre suas atividades de aprendizagem, gerenciando o tempo e a qualidade da sua formação e, sobretudo, avaliando constantemente a própria conduta. Assim, para Rué (2007):

${ }^{2}$ Dicionário Michaelis. Disponível em: $<\mathrm{http}: / /$ michaelis.uol.com.br/busca? $\mathrm{r}=0$ \& $\mathrm{f}=0$ \& $\mathrm{t}=0$ \&palavra=a utonomia>. Acesso em: 28 jul. 2016. 
- Você sabe o que faz e o que é, tem um certo autocontrole sobre os objetivos da sua atividade de aprendizagem.

- É algo que atribui sentido, isto é, algo que implica, de alguma forma, seu próprio ponto de vista (e ainda melhor se envolve emocionalmente). - Exerce um grau de controle sobre os recursos, horários, procedimentos e qualidade do que está sendo executado.

- Ele tem um elemento de apoio, como referência, e contraste (sociais, informativo ou processual) para avaliar os seus próprios comportamentos ou resultados (RUÉ, 2007, p. 6) . $^{3}$

Diante disso, percebe-se que para se produzir o discipulus iacto a/o estudante deve exercer uma série de operações sobre si que caracterizam essa posição de sujeito, tais como: o autocontrole sobre o próprio processo de aprendizagem, o controle do tempo e a autoavaliação constante de suas condutas (LEAL, 2017). Nesse sentido, a técnica da autonomia atua conduzindo as ações das/os alunas/os para que elas/es aprendam a se autocontrolar e autoavaliar. Para que isso ocorra, as/os professoras/ es universitárias/os buscam conhecer e desenvolver processos de ensino que incitam a autonomia estudantil, a fim de constituírem uma docência inovadora no ensino superior, como no excerto a seguir.

Desta forma, com uma abordagem metodológica diferenciada cumpre a proposta da ementa de "desenvolver a capacidade de leitura" de uma forma não mecanicista ou reprodutiva, mas formativa e reflexiva, trabalhando autoavaliação, e avaliação coletivamente construída, que enriqueceu o processo de trabalho autoconfiança e desenvolvimentos

${ }^{3}$ Tradução livre de: "Sabe qué hace y para qué, es decir, ejerce un cierto autocontrol sobre las finalidades de su actividad de aprendizaje.

- Hace algo a lo cual atribuye sentido, es decir, algo que le implique, de algún modo, en su propio punto de vista (y mejor aún si se le implica emocionalmente).

- Ejerce un determinado grado de control sobre los recursos, los tiempos, los procedimientos y la calidad de lo que está ejecutando.

- Dispone de algún elemento de apoyo, como criterio de referencia, y de contraste (social, informativo o procedimental) para poder evaluar las propias conductas o resultados" (RUÉ, 2007, p. 6). 
de autonomia crítica sobre o que eles, enquanto alunos, estão fazendo, e o quanto eles são responsáveis por isso (Trecho do Plano de ação docente Enif).

É possível observar que o desenvolvimento da autonomia estudantil foi proporcionado pela inserção da autoavaliação e da avaliação coletiva, no plano de ação inovador da docente Enif, reiterando a corresponsabilização das/os discentes no seu próprio processo de aprendizagem, ou seja, "o quanto eles são responsáveis por isso" (LEAL, 2017). Depreende-se, portanto, que o autogoverno discente é incitado nas práticas educativas consideradas inovadoras. Na perspectiva foucaultiana, autogoverno seria a relação que o sujeito estabelece consigo mesmo. Ele dirige a si mesmo toda uma série de exercícios, em que se autoquestiona, reflete sobre a sua conduta e questiona as suas ações para aprender. Nesse sentido, a autoavaliação pode funcionar como técnica de si, pois ela "refere-se ao processo pelo qual o próprio aluno analisa continuamente as atividades desenvolvidas e em desenvolvimento, registra suas percepções e seus sentimentos e identifica futuras ações, para que haja avanço na aprendizagem" (VILLAS BOAS, 2008, p. 51). Para Villas Boas (2008), essa análise conduz a/o discente a se perguntar: o que aprendeu? $\mathrm{O}$ que ainda não aprendeu? $\mathrm{O}$ que facilitou e/ou dificultou a sua aprendizagem? Dessa maneira, a/o estudante se autoquestiona no sentido de perceber as suas condutas a fim de reconduzi-las para uma aprendizagem efetiva.

De acordo com Leal, no ensino visto como tradicional, cabia usualmente à/ao professora/or realizar sozinha/o a avaliação da aprendizagem. No caso da autoavaliação, a/o estudante participa também desse processo. Ao se autoavaliar, a/o discente regula a ação da sua própria aprendizagem. Esse processo envolve a regulação da ação de aprender (VILLAS BOAS, 2008, p. 53). É como se o sujeito se olhasse ao agir. Tratase de um olhar sobre o que se está fazendo, enquanto se faz, de maneira contínua. É possível pensar, portanto, que a autoavaliação constitui em uma técnica para governo de si. Para Villas Boas (2008, p. 54), "por meio 
da autoavaliação, atinge-se o desenvolvimento das atividades cognitivas como forma de melhoria da regulação das aprendizagens, pelo aumento do autocontrole e pela diminuição da regulação externa do professor". Com isso, "almeja-se prioritariamente o desenvolvimento da autonomia do aluno” (VILLAS BOAS, 2008, p. 54). O dispositivo da inovação aciona, portanto, o autogoverno discente para se produzir estudantes autônomas/os e ativas/os (LEAL, 2017).

A posição de sujeito discipulus iacto tem a participação e o envolvimento discente como sua marca constitutiva, conforme trecho da entrevista com a docente Kajam.

\begin{abstract}
Discipulus Iacto
Eles [os estudantes] pedem para ver o conteúdo antes, que eles têm essa necessidade de ver antes, pra eles conseguirem debater. É uma estratégia, eu vejo como uma estratégia deles para utilizar a questão da aprendizagem deles, da concentração, porque, se eles ficarem extremamente pacíficos no processo, eles vão cochilar, eles vão dormir, o cansaço vai vencer eles. Então eu vejo que a demanda deles é muito dessa ordem, compensar o tempo que eu estou aqui, e pra isso eu preciso participar mais, me envolver mais (Trecho da entrevista docente - Kajam).
\end{abstract}

Nesse sentido, as/os estudantes buscam estudar o conteúdo antes das aulas presenciais - segundo Kajam "eles pedem para ver o conteúdo antes". A professora afirma que essa constitui-se numa "estratégia" das/os discentes a fim de desenvolverem a própria aprendizagem e não se tornarem "pacíficos no processo". Assim, elas/es participam e se envolvem mais. Entretanto, Kajam ressalta que não são todos as/os estudantes que desejam participar muito das aulas.

Porém isso não é, isso não são todos os alunos, a gente ainda tem um grupo de alunos que demanda a aula no modelo convencional, ele entende que se ele participar muito, ele não está tendo aula, ele está 
dando aula, então alguns alunos ainda confundem (Trecho da entrevista - docente Kajam).

Para a professora Kajam algumas/uns estudantes entendem que, se participarem muito, estarão ministrando as aulas e assumindo um lugar que seria da/o professora/or. De acordo com Marin (2010), ao analisar as fragilidades no uso das metodologias inovadoras, especialmente as consideradas ativas, sob a ótica das/os estudantes, concluiu-se que elas/es se sentem perdidas/os quando se utiliza esse tipo de metodologia em alguns momentos do curso, especialmente em disciplinas básicas.

Portanto, a produção da posição discipulus iacto é um dos efeitos das relações de poder que se faz presente no dispositivo de inovação no sentido de os sujeitos atuarem de maneira ativa no seu processo de aprendizagem. Está "no verdadeiro" do discurso de inovação, constituinte do dispositivo, o entendimento de que se a/o professora/or atuar como mediadora/or a/o estudante poderá agir de maneira ativa, ser parceira/o e corresponsável por sua aprendizagem (LEAL, 2017). Nessa direção, haveria uma continuidade discursiva entre docência inovadora e discipulus iacto. Porém, isso pode não acontecer necessariamente, pois nesse processo incidem relações de forças que limitam ou dificultam tal atuação, podendo esta, assim, ter outros efeitos.

\section{Considerações finais}

Constatamos que as/os discentes são incitadas/os a autogovernarem suas condutas para aprenderem permanentemente por meio da busca de formação contínua, do protagonismo e da corresponsabilização da aprendizagem. No material analisado, é divulgado que, para isso, as/ os discentes precisam "ser autônomas/os", "protagonistas do seu aprendizado" e "corresponsabilizar-se por sua formação". É possível notar que a ação da/o estudante é conduzida para que ela/e participe das decisões do seu processo de aprendizagem. Nesse sentido, o protagonismo é acionado no dispositivo de inovação como uma técnica de governo que incide 
sobre a conduta das/os estudantes. Outra técnica de governo acionada no dispositivo de inovação é a autonomia. Sendo assim, as/os docentes do ensino superior estão sendo convocadas/os a atuar como mediadoras/es nos processos de ensinar e aprender no intuito de fomentar o autogoverno discente para a atuação na "sociedade da inovação".

Diante disso, percebe-se que para se produzir o discipulus iacto a/o estudante deve exercer uma série de operações sobre si mesma/o que caracterizam essa posição de sujeito, tais como: o autocontrole sobre o próprio processo de aprendizagem, o controle do tempo e a autoavaliação constante de suas condutas. Nesse sentido, a técnica da autonomia atua conduzindo as ações das/os alunas/os para que elas/ es sejam autônomas/os, aprendam a se autocontrolar e autoavaliar. Depreende-se, portanto, que o autogoverno discente é incitado nas práticas educativas consideradas inovadoras (LEAL, 2017). Para que isso ocorra, as/os professoras/es universitárias/os precisam se formar continuamente, conhecer e desenvolver processos de ensino que incitam a autonomia estudantil, a fim de constituírem uma docência inovadora no ensino superior.

Tais práticas pedagógicas colocadas em funcionamento pelo dispositivo de inovação incitam as/os estudantes a dirigirem a si mesmas/os toda uma série de exercícios, em que se autoquestionam, refletem sobre a sua conduta e questionam as suas ações para aprender. Aciona-se, portanto, o autogoverno discente para se produzir estudantes autônomas/os e ativas/os. Enfim, foi possível observar que a inovação demandada discursivamente não é de qualquer tipo: trata-se de uma inovação regulada.

\section{Referências}

AMARAL, A.; NATAL, G.; VIANA, L. Netnografia como aporte metodológico da pesquisa em comunicação digital. Sessões do imaginário, Porto Alegre, n. 20, p. 34-40, dez. 2008. 
CUNHA, M. I. Inovações pedagógicas: o desafio da reconfiguração de saberes na docência universitária. São Paulo: USP, 2008. (Cadernos pedagogia universitária, v. 6).

FERRETTI, C. I.; ZIBAS, D. M. L.; TARTUCE, G. L. B. P. Protagonismo juvenil na literatura especializada e na reforma do ensino médio. Cadernos de pesquisa, v. 34, n. 122, p. 411-423, mai./ago. 2004.

FOUCAULT, M. Verdade e subjetividade. Revista de Comunicação e linguagem, Lisboa, n. 19, p. 203-223, 1993.

FOUCAULT, M. As palavras e as coisas: uma arqueologia das ciências humanas. São Paulo: Martins Fontes, 1999.

FOUCAULT, M. Estratégia, poder-saber. 2. ed. Rio de Janeiro: ForenseUniversitária, 2006. (Coleção ditos \& escritos, v. 4).

FOUCAULT, M. Segurança, território, população. Curso dado no Collège de France (1977-1978). Trad. E. Brandão. São Paulo: Martins Fontes, 2008.

FOUCAULT, M. Estratégia, poder-saber. 2. ed. Rio de Janeiro: ForenseUniversitária, 2010. (Coleção ditos \& escritos, v. 4).

FOUCAULT, M. Do governo dos vivos: curso no Collége de France (1979-1980). São Paulo: Editora WMF Martins Fontes, 2014.

FOUCAULT, M. História da sexualidade 1: a vontade de saber. 3. ed. São Paulo: Paz e Terra, 2015.

KOZINETS, R. V. Netnografia: realizando pesquisa etnográfica online. Porto Alegre: Penso, 2014.

LEAL, R. E. G. Dispositivo de inovação no ensino superior: a produção do docentis innovatus e discipulus iacto. Dissertação (Mestrado) - Faculdade de Educação, Universidade Federal de Minas Gerais, Belo Horizonte, 2017.

LEITE, D. Desafios para a inovação pedagógica na universidade do século 21. Revista da FAEEBA - Educação e Contemporaneidade, Salvador, v. 21, n. 38, p. 29-39, jul./dez. 2012. 
MACHADO, R. Introdução por uma genealogia do poder. In: FOUCAULT, M. Microfísica do poder. 28. ed. Rio de Janeiro: Paz e Terra, 2014.

MARIN, M. J. S. et al. Aspectos das fortalezas e fragilidades no uso das metodologias ativas de aprendizagem. Revista brasileira de educação médica, Rio de Janeiro, v. 34, n. 1, p. 13-20, jan./mar. 2010.

PARAIISO, M. A. Currículo e mídia educativa brasileira. Chapecó: Argos Editora Universitária, 2007.

RUÉ, J. El aprendizaje en Autonomía, posibilidades y límites. In: SIMPÓSIO INTERNACIONAL RED-U 2-07: EL DESARROLLO DE LA AUTONOMÍA EN EL APRENDIZAJE, 2007, Barcelona. Actas... Barcelona: RED-U; U. Pompeu Fabra, 2007. Disponível em: <http://congresos.um.es/redu/barcelona2007/paper/ view/441/411>. Acesso em: 07 mar. 2019.

SARAIVA, K. Pensando a educação a distância a partir de lições aprendidas com Foucault. Muitas Vozes, Ponta Grossa, v. 2, n. 1, p. 11-29, 2013.

SILVEIRA, R. M. H. A entrevista na pesquisa em educação - uma arena de significados. In: COSTA, M. V. (Org.). Caminhos investigativos II: outros modos de pensar e fazer pesquisa em educação. 2. ed. Rio de Janeiro: Lamparina editora, 2007.

SOUZA, M. A. de. A propósito do protagonismo juvenil: quais discursos e significados? 2011. 151f. Dissertação (Mestrado em Sociologia) — Universidade Federal do Ceará, Fortaleza, 2011.

TEIXEIRA, I. A. C.; PADUA, K. C. Virtualidades e alcance das entrevistas narrativas. In: CONGRESSO INTERNACIONAL SOBRE PESQUISA (AUTO) BIOGRÁFICA, 2., 2006, Salvador. Anais... Salvador: [s.n], 2006. (CD-ROM).

UNIVERSIDADE FEDERAL DE MINAS GERAIS (UFMG). Relatório 2010-2013: Percursos Formativos de docentes do ensino superior. Belo Horizonte: Diretoria de Inovação e Metodologias de ensino, 2014.

UNIVERSIDADE FEDERAL DE MINAS GERAIS (UFMG). Projeto Pedagógico do Curso de Graduação em Enfermagem da Universidade Federal de Minas Gerais. Belo Horizonte: Escola de Enfermagem, 2015. 
22 SALES, S. R.; LEAL, R. E. G.

VEIGA-NETO, A. Foucault \& a Educação. 3. ed. Belo Horizonte: Autêntica, 2011.

VILLAS BOAS, B. M. de F. Portfólio, avaliação e trabalho pedagógico. 5. ed. Campinas: Papirus, 2004.

Recebido: 04/12/2018

Received: 12/04/2018

Recibido: 04/12/2018

Aprovado: 11/02/2019

Approved: 02/11/2019

Aprobado: 11/02/2019 